\title{
Back to the future: the JLO electronic archive
}

\begin{abstract}
2007 has been an eventful year for The Journal of Laryngology \& Otology. The principal event has been the completion of the electronic archive. This has been a major project which has culminated in the production of a fully searchable archive of Journal content from its inception in 1887. This work has been a collaboration between The Journal and our publishers, Cambridge University Press. Special mention must go to Daniel Edwards, who painstakingly supervised the copying, digitisation and cataloguing of every single page of The Journal ever published. The Editors also thank Neil Weir and the library of University College, London, for making copies of The Journal available for processing. The completed archive has been available online since June 2007 through the JLO website (www.jlo.co.uk). Journal subscribers can download articles free of charge in portable document file (pdf) format. Article downloads are also available to non-subscribers on a 'pay per view' basis.
\end{abstract}

For those with an interest in the history of otolaryngology, searching the archive is a fascinating exercise. It is particularly informative to discover that issues that are regarded as contemporary have been under active discussion over a century previously. For example, in 'The anatomy of the frontal sinus and the anterior ethmoidal cells', Hartmann contends that 'it is not sufficient to remove the floor of the frontal sinus, but that the floor of the frontal cells must also be removed, in order to obtain a free communication between the frontal sinus and the nose'. ${ }^{1}$ This is clearly the equivalent of the 'uncapping the egg' concept advocated by modern endoscopic sinus surgeons in approaching the frontal sinus. It is also of interest to follow the documentation of early attempts at treatment such as radiotherapy. Strandberg ${ }^{2}$ eloquently describes a case of radionecrosis of the larynx in 'Injury to the larynx induced by X-ray treatment'. Some of the most amusing aspects of the archive are the advertisements, an example of which is that for the 'intranasal ionizer' for applying galvanic current to the nasal cavity ${ }^{3}$ for the treatment of hay fever and nonsuppurative rhinitis. It is also through observation of the extent of the archive that one appreciates, as Editors, the responsibility of maintaining the integrity of The Journal through our short period of stewardship.

There have been other developments of an electronic nature, coordinated by our Web Editor, Nitesh Patel. It is now possible to download The Journal to a personal digital assistant device. In addition, subscribers can view presentations given by Royal Society of Medicine / Journal of Laryngology \& Otology visiting professors by streaming video via The Journal's website. The excellent presentations of Professors Gayle Woodson and Vincent Cousins are available to view online. Virtually all submissions to The Journal are now electronic. Authors can now track the progress of their papers online and upload revisions directly to the website. Once accepted for publication, proofread and copy-edited, papers are published online as 'forthcoming articles' with their own unique, citable 'digital object identifier' number.

The Journal continues to receive a healthy number of articles submitted for publication, of which approximately one-third are accepted. Over the past year, the trend toward publishing more Main Articles has continued. Clinical Records are still considered, but need to have an important clinical message in order to justify publication. Accepted Clinical Records are more likely to be published as 'online only' articles. With an increasing number of Main Articles and Reviews, The Journal's impact factor has continued its progressive, year on year increase. While this is welcome, we acknowledge that the impact factor as a measure of publication quality has been widely discredited by many in the academic world. Our intention is to publish readable articles that are of genuine interest to the otolaryngology community in its widest sense. The Journal continues to receive submissions from all four corners of the globe, reflecting the international outlook of our publication. We are particularly keen to engage with otolaryngologists in the rapidly developing nations of South Asia, South East Asia, China and Africa. Over the forthcoming months, we shall be examining ways in which the electronic version of The Journal can be made more freely available to otolaryngologists in the developing world.

As always, we are extremely grateful for the efforts of our Assistant Editors in providing timely peer review of articles submitted to The Journal. This year has seen Abir Bhattacharyya, Bhik Kotecha and Alessandra Rinaldo join us as Assistant Editors. Steven Zeitels and Saumil Merchant have retired from our Editorial Board, and we thank them for their work on behalf of The Journal. Particular mention should go to Liam Flood, our Senior Assistant Editor and Book Review Editor, for the considerable volume of work undertaken for The Journal. In the forthcoming year, The Journal will be commencing an initiative in which additional copies of books received for review will be made available to trainee subscribers - details to follow.

The issue of author misconduct continues to be actively discussed in the publishing world. The availability of software to detect duplicate publication and plagiarism has made the detection of publication 
fraud significantly easier. The Journal's policy on author misconduct is available to view on the website.

We must once again thank our Managing Editor, Rosamund Greensted, for her continued enormous effort on behalf of The Journal. There is no doubt that Rosamund's diligence, combined with her extensive experience in the publishing world, has been a major factor in The Journal's current healthy position. Appreciation is also due to Michael Hellyer, the Company Secretary of JLO (1984) Ltd, for overseeing the commercial aspects of The Journal in such an effective manner. Our collaboration with Cambridge University Press continues to flourish, and we thank Daniel Edwards, Sue Perkins and Sarah Sharpe for their work on behalf of The Journal.

Finally we thank you, our readers and subscribers, for continuing to support The Journal. We are always receptive to feedback, and any suggestions for the development of our publication would be received with interest. We wish you a successful 2008 and hope that you continue to enjoy reading The Journal of Laryngology \& Otology in whatever form, paper or electronic, that you prefer.

\section{References}

1 Hartmann A. The anatomy of the frontal sinus and the anterior ethmoidal cells. J Laryngol Otol 1900;15:64-5

2 Strandberg O. Injury to the larynx induced by X-ray treatment. J Laryngol Otol 1924;39:437-40

3 Anonymous. The Intra-nasal Ionizer. J Laryngol Otol 1932; 47(7):vi

Robin Youngs

GuY KENYON

JLO EDITORS 